\title{
ON INFERRING STANDARD DEVIATIONS FROM PATH DEPENDENT OPTIONS
}

\author{
Clifford A. BALL, Walter N. TOROUS and Adrian E. TSCHOEGL * \\ University of Michigan, Ann Arbor, MI 48109-1234, USA
}

Received 15 January 1985

Path dependent option prices are employed to derive implied standard deviations of the underlying security price process without recourse to numerical procedures. We empirically illustrate our methodology by inferring the volatility of gold prices.

\section{Introduction}

In this paper we use path dependent option prices to derive implied standard deviations of the underlying security price process based upon Goldman et al.'s (1979) 'buy at the low, sell at the high' options. The value of a straddle position involving both these path dependent call and put options reflects the expected range of the underlying security price. The resultant ex ante measures of security price volatility effectively utilize this information and, significantly, require no recourse to numerical procedures in their computation.

On March 16, 1982, Mocatta Metals Corporation of New York introduced 'lookback' options, precisely 'buy at the low, sell at the high' options. A lookback put gives its owner the right to sell gold, silver or platinum at its ex post realized high, whereas a lookback call gives its owner the right to purchase the precious metal at its ex post realized low. We illustrate our methodology and its advantages by computing lookback implied standard deviations ( $L I S D$ s) for gold.

\section{Methodology}

A call option which gives its owner the right to purchase the underlying security at its lowest realized price has a terminal payoff of

$S(T)-\min _{0 \leq \tau \leq T} S(\tau)$

whereas a put option which gives its owner the right to sell the underlying security at its highest realized price has a terminal payoff of

\footnotetext{
* We would like to thank William Bradna of the Siegel Trading Company for supplying us with the lookback option price data. Sayan Chatterjee and K. Rajan Palani provided excellent research assistance. Any remaining errors are the authors' responsibility.
} 
$\max _{0 \leq \tau \leq T} S(\tau)-S(T)$,

where $S$ is the underlying security price and $T$ is the term to expiration of the options. The investor purchasing both the call and the put, a straddle, then enjoys the following terminal payoff:

$$
\max _{0 \leq \tau \leq T} S(\tau)-\min _{0 \leq \tau \leq T} S(\tau) \text {. }
$$

This is simply the range of the underlying security price over the term to expiration of the options.

Intuitively, the current price of this straddle must provide information regarding the expected range of the underlying security price. The expected range, in turn, provides information on the expected standard deviation of the underlying security price process. Recall that by taking advantage of the informativeness of security price range, Parkinson (1980) developed a statistically efficient ex post estimator of security price volatility.

Following Goldman et al. (1979) we assume that the logarithm of the underlying security price is governed by the non-standardized Wiener process

$\mathrm{d} \ln S=\sigma \mathrm{d} Z$,

where $\sigma$ is the instantaneous standard deviation to be implied and $Z$ is a standardized Wiener process. Under these assumptions, Goldman et al. establish that in a perfect financial market the initial equilibrium price of the straddle which gives its owner the right to purchase the underlying security at its low price and sell at its high price is given by

$C_{\min }+P_{\max }=2 S(1-2 N\{-\sigma \sqrt{T}\})$,

where $C_{\min }$ and $P_{\max }$ denote the initial equilibrium prices of the lookback call and put, respectively, and $N(\cdot)$ denotes the standard normal cumulative distribution function. Here $T$ is measured in years. A Maclaurin series expansion reveals that

$1-2 N\{-\sigma \sqrt{T}\}=(2 / \sqrt{2 \pi}) \sigma \sqrt{T}+$ higher-order terms.

Ignoring higher-order terms and assuming the resultant approximation holds as an equality,

$\sigma=\left(\left(C_{\min }+P_{\max }\right) / S\right) \sqrt{\pi / 8 T}$.

Significantly, numerical procedures are not required to estimate the standard deviation of the underlying security price process.

\section{Empirical results}

Our data consists of the daily quoted prices of 90 and 180 day gold lookback put and call options over the period 16 March to 20 April, 1982. These options are sold daily by Mocatta Metals Corporation and no corresponding secondary market exists. Valuation at their inception is therefore appropriate. The London P.M. fixing provides the underlying gold price. All gold data is from markets in which prices are quoted in U.S. dollars, so exchange rate adjustments are not necessary.

Employing expression (5), fig. 1 presents the resultant 90 and 180 day gold LISDs. Note the consistency across these ex ante measures of gold volatility. The 90 and 180 day gold lookback option prices yield nearly identical estimates of gold volatility. 


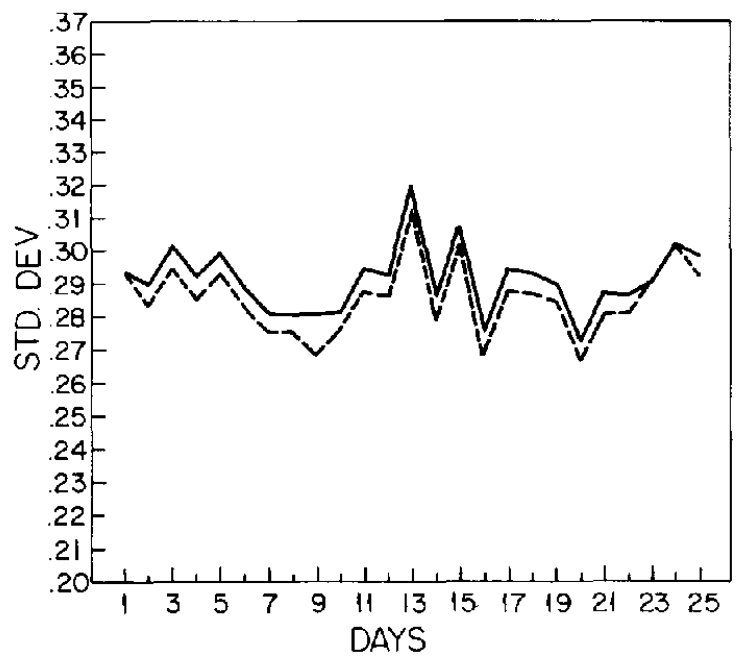

Fig. 1.

For comparison purposes, we assume the validity of the Black-Scholes (1973) equilibrium call option price formulation and numerically compute gold implied standard deviations (ISDs) for the same time period given path independent gold call option prices from the European Options Exchange's gold options market [Ball et al. (1985)]. We employ the closing prices of at-the-money gold call options with term to expiration ranging from 80 to 105 days. The resultant ISDs possess maximum predictive ability, exceeding even the informativeness of weighted ISDs [Beckers (1981)]. Gold pays no dividends and hence dividend adjustments are unnecessary. The risk-free rate of interest used is the rate of return to a U.S. Treasury bill maturing closest to the expiration date of the option. Fig. 2 provides the results, together with corresponding 90 day gold LISDs. Both ex ante

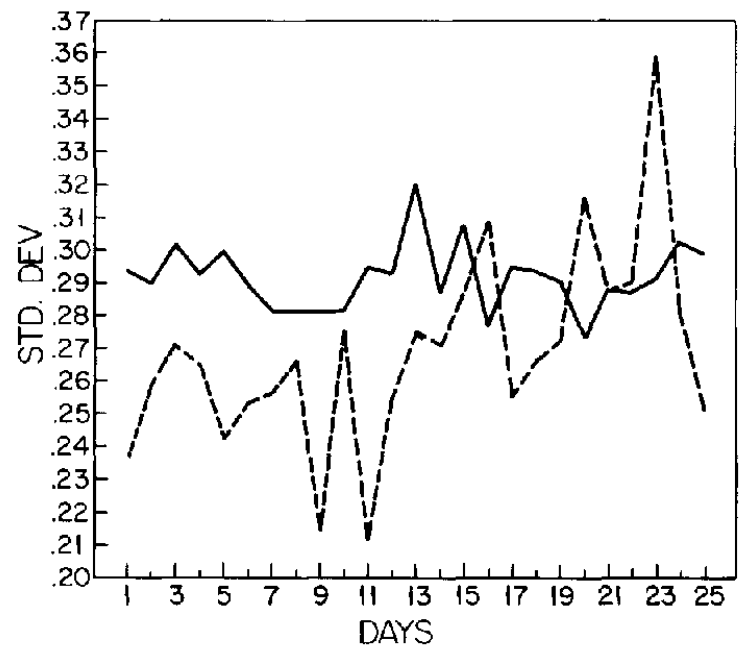

Fig. 2. 
measures of gold volatility are in broad agreement. However, gold LISDs are more stable than gold $I S D$ s over the time period under investigation. Gold ISDs are subject to sizeable variation on a day-to-day basis. The extreme volatility of $I S D$ s has been noted by others [MacBeth and Merville (1979)]. By contrast, LISDs appear to be more consistent with the underlying assumption of constant security volatility.

\section{Conclusions}

We have derived an ex ante measure of security price volatility based upon Goldman et al.'s (1979) 'buy at the low, sell at the high' options which requires no recourse to numerical computation for its implementation. The advantages of the resultant estimator derive from the fact that the $L I S D$ is based upon a straddle involving a lookback call and put, the current value of this straddle reflecting the expected range of the underlying security price.

Given the available gold lookback option price data, we restricted attention to LISDs based upon the equilibrium valuation of these path dependent options at their inception. Relaxing this assumption would require that $L I S D_{\mathrm{s}}$ be evaluated numerically. The aforementioned advantages of LISDS would remain.

Standard deviations implied from path dependent options can be utilized in the valuation of path independent options. With growth in option markets, the increased availability of path dependent options will enhance the applicability of these results.

\section{References}

Ball, Clifford A., Walter N. Torous and Adrian E. Tschoegl, 1985, An empirical investigation of the EOE gold options market, Journal of Banking and Finance 9, no. 1.

Beckers, Stan, 1981, Standard deviations implied in option prices as predictors of future stock price variability, Journal of Banking and Finance 5, 363-381.

Black, Fischer and Myron Scholes, 1973, The pricing of options and corporate liabilities, Journal of Political Economy 81 , 637-654.

Goldman, M. Barry, Howard B. Sosin and Mary Ann Gatto, 1979, Path dependent options: 'Buy at the low, sell at the high', Journal of Finance 34, 1111-1127.

MacBeth, James D. and Larry J. Merville, 1979, An empirical investigation of the Black-Scholes call option pricing model, Journal of Finance 34, 1173-1186.

Parkinson, Michael, 1980, The extreme value method for estimating the variance of the rate of return, Journal of Business 53 , $61-65$. 